\title{
Effect of Surfactant in Particle Shape and Thermal Degradation of Eggshell Particles
}

\author{
Diana Samantha Villarreal-Lucio ${ }^{a}$,Jose Luis Rivera Armenta ${ }^{a}{ }^{\circledR}$, Iván Alziri Estrada Moreno ${ }^{b}$, $^{-}$ \\ Ricardo Garcia-Alamilla ${ }^{a}$
${ }^{a}$ Centro de Investigación en Petroquímica, Tecnológico Nacional de México, Instituto Tecnológico de Ciudad Madero, 89600, Altamira, TAMS, México \\ ${ }^{b}$ CONACYT-CIMAV S.C., Centro de Investigación en Materiales Avanzados S.C., Chihuahua, Chih. \\ 31136, México
}

Received: November 30, 2018; Revised: February 12, 2019; Accepted: March 21, 2019

\begin{abstract}
High energy ball milling and sonofragmentation were used successfully to reduce the crystallite size of calcium carbonate extracted from the eggshell. The ceramic was milled using either deionized water or stearic acid and then subjected to a subsequent size reduction by means of a tip horn. The thermal degradation of particles was influenced by the presence of stearic acid in milling process because it acts as a protective layer around eggshell particles. It was found that the reduction in crystallite size diminishes the degradation temperature and the presence of the surfactant may lead to a change in particle shape by trough a superplasticity phenomenon. Tubes, fibers and a rectangular prism were observed in Transmission Electron Microscopy.
\end{abstract}

Keywords: crystallite size reduction, sonofragmentation, eggshell, superplasticity.

\section{Introduction}

Eggs are considered a basic product in Mexican homes, México is ranked in fourth place in worldwide production with more than 2.5 millions of tons of fresh egg ${ }^{1}$. Not only, the egg withe can be utilized, but also, it is possible to take advantage of the residues: eggshell membranes and eggshell. This means that egg byproducts can be used in many applications, from the simplest but useful like mixing the eggshell with waste of rice, potatoes and grass to produce a compost that reduce the content of lead ${ }^{2}$, to more complex like the utilization of membranes in the detection of urea ${ }^{3}$.

On the other hand $\mathrm{CaCO}_{3}$ has been widely studied due to its chemical stability and mechanical reinforcement ability ${ }^{4-6}$. Lately, particle size has taken importance in tailoring final properties of $\mathrm{CaCO}_{3}$-composites and in the ceramic material itself. Several efforts have been made in order to achieve the nanometer size. For calcium carbonate the bottom-up method has been preferred, because it is easier to control size and morphology of particles ${ }^{7-8}$. However, top-down technics have been applied successfully to obtain $\mathrm{CaCO}_{3}$ nanoparticles. Hassan et al. (2014) ${ }^{9}$ reported a size reduction of eggshell particles until $10 \mathrm{~nm}$ by using a process of $10 \mathrm{~h}$ milling followed by the passage of ultrasound in a slurry of ES and dimethylformamide. Mosaddegh (2013) ${ }^{10}$ applied a similar but shorter process to get eggshell nanoparticles, other works reports the use of ultrasound process as a good path for crystallite size reduction ${ }^{11-12}$.

It is well known that the passage of ultrasound in a liquid leads to an acoustic cavitation phenomenon implaying the

"e-mail: jlriveraarmenta@itcm.edu.mx. increase of temperature and pressure ${ }^{13}$. After the implosion other secondary effects appear: microjets, micro streams, shock waves, turbulence, shear forces, etc ${ }^{14}$. Microstreams drive the smallest particles and also make them hit each other ${ }^{15}$. The results of these secondary effects are deaglomeration and particle size reduction (sonofragmentation) $)^{16}$, the enhancement of chemical reactions (sonochemistry) ${ }^{17}$, the growth of crystals (sonnocrystalization) ${ }^{16}$, the dispersion and stabilization of emulsions ${ }^{18}$, and others like mixing, surface cleaning, dispersing, cell disruption, degassing, etc ${ }^{19}$.

Sonofragmentation studies as a discipline has been made previously ${ }^{20-21}$. But for sonofragmentation of ceramics the breakage of particles is controlled by the shock wave itself $\mathrm{f}^{22}$ the slurry concentration is independent of sonofragmentation, and this leads that particle-particle collisions have not a dominant effect on size reduction.

In this investigation a combination of high-energy ball milling and sonofragmentation was applied to get stable nanoparticles, the method proposed by Hassan et al. $(2014)^{9}$ was slightly modified and nanoparticles were characterized by means X-Ray Diffraction (XRD), Thermogravimetric analysis (TGA) and Transmission electron microscopy (TEM) in order to evaluate the effect of method in crystallite size.

\section{Methods}

\section{$2.1 \mathrm{CaCO}_{3}$ particles size reduction}

After eggshells collected from household were washed a first size reduction was done using a blender, afterward, the powder was soaked in acetone for $2 \mathrm{~h}$ in order to separate the $\mathrm{CaCO}_{3}$ from organic compounds, this sample was designed 
as "B", a second size reduction of $\mathrm{CaCO}_{3}$ particles $\left(\mathrm{M}_{10}\right)$ was performed in a SPEX $8000 \mathrm{M}$ high energy ball mill during $10 \mathrm{~h}$ using as lubricant either $10 \mathrm{ml}$ of distillated water (wet milling) or stearic acid (SA) (dry milling), (subscript in M indicate the ball milling time, subscript in US indicates the amplitude in ultrasound conditions respectively), in a 10/1 ratio (liquid/solid). Finally, both groups of particles were sonicated, using distillated water for particles milled in water and alcohol for particles milled in SA, for 1 and $5 \mathrm{~h}\left(\mathrm{M}_{10} \mathrm{US}\right)$ (samples were identified as $\mathrm{C}-\mathrm{M}_{10} \mathrm{US}_{50} \mathrm{t}=1$ and $\mathrm{C}-\mathrm{M}_{10} \mathrm{US}_{50}$ $\mathrm{t}=5$ respectively) [9] using a UP200Ht Hielscher ultrasonic horn, with a $26 \mathrm{KHz}$ frequency and a tip diameter of $7 \mathrm{~mm}$.

\subsection{Characterization methods}

In order to know the crystal structure of $\mathrm{CaCO}_{3}$ extracted from eggshell, and all samples after each size reduction step, an X-ray diffraction analysis (XRD) was performed using a Bruker Advance D8 diffractometer with monocromatic $\mathrm{Cu}-\mathrm{k} \alpha$ radiation, wavelenght $(\lambda)$ of $0.15406 \mathrm{~nm}$, in a range of 20 to $80^{\circ}(2 \theta)$ with a scanning speed of $4^{\circ} / \mathrm{min}$. From the XRD patterns the crystallite size was calculated based on the Scherrer equation and using the ( $\mathrm{h} \mathrm{kl}$ ) indexes corresponding to $\left(\begin{array}{lll}1 & 0 & 4\end{array}\right)$ signal of calcite:

$$
D_{104}=\frac{k \cdot \lambda}{\beta_{104} \cos \theta}
$$

Where $k$ is a shape factor (0.9), $\lambda=0.15406 \mathrm{~nm}, \beta$ is the full width at half maximum (FWHM) and $\theta$ is the angle of (1 04 ) peak. The thermal degradation behavior of all samples was studied by means of a SDT TA Instruments model Q600 analyzer, from ambient temperature until $1000{ }^{\circ} \mathrm{C}$, with a heating rate of $10^{\circ} \mathrm{C} / \mathrm{min}$, in a nitrogen atmosphere. The morphology of $\mathrm{CaCO}_{3}$ nanoparticles was observed in a JEOL JEM-1010 with a voltage operation at $80 \mathrm{kV}$. The samples were prepared using routine methods.

\section{Results}

The Figure 1 shows X-ray diffractogram for samples $\mathrm{B}, \mathrm{M}_{10}$ and $\mathrm{C}-\mathrm{M}_{10}$, the characteristic pattern of calcite is observed in all of them. The peak at $2 \theta=29.4$ is representative of calcite, there is only few differences among the intensity of this peaks, which can be translate into changes in crystallite size, small and broad peaks means a smaller crystallite ${ }^{23}$. Table 1 display the size of crystallite of each sample. After the size reduction made with a blender the crystal size is $51.9 \mathrm{~nm}$, during the ball milling using water as lubricant the crystal is reduce until $30.1 \mathrm{~nm}$, while for those milled with SA the crystallite size is $23.3 \mathrm{~nm}$. It can be observed the crystalline size reduction, because the impact of the balls leads to deformation and loss of crystallinity ${ }^{24-26}$.

The eggshell particles suspended in ethanol and water, do not show a crystallographic change, remaining calcite structure in all samples. The data presented in table 1 indicates

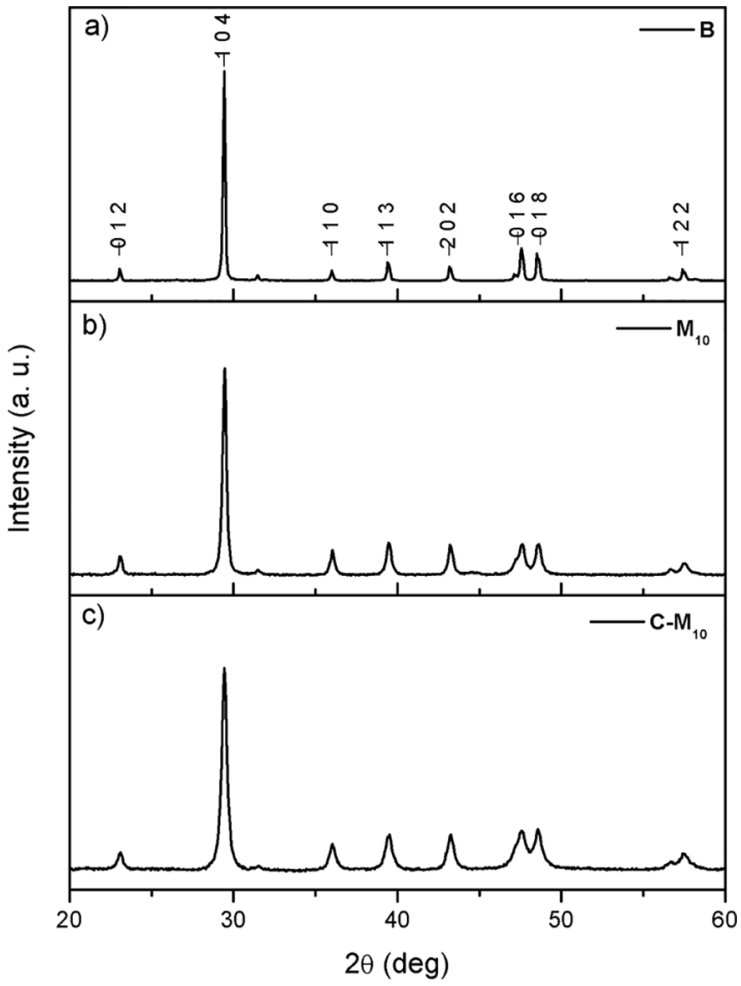

Figure 1. X-ray diffraction patterns of $\mathrm{CaCO}_{3}$ extracted from eggshell: a) after the first size reduction using a blender (B), b) after being ball milled in water for $10 \mathrm{~h}$ and $\left.\left(\mathrm{M}_{10}\right), \mathrm{c}\right)$ and after being ball milled in stearic acid for $10 \mathrm{~h}\left(\mathrm{C}-\mathrm{M}_{10}\right)$.

that $\mathrm{SA}$ reduces the crystalline size. This may be explained because there are 2 mechanisms which take place during a grinding with additives, one is based on the reduction of surface energy and the other one is due to surface hardness ${ }^{27-28}$. The second mechanism is flowability, and it also has to do with the reduction of surface energy. Moreover, SA is considered an internal and external lubricant, namely, reduces friction among particles, and between particles and in the mill internal surface ${ }^{29-30}$, and this also increase flowability. Comparing the influence that water and $\mathrm{AE}$ have during the milling, it can be observed that the effect of SA takes $\mathrm{CaCO}_{3}$ particles to a lower crystalline sizes, both, water and SA increase flowability, but only SA can remain particles separated once the process is over.

Table 1 shows results of crystallite size after sonofragmentation. Particles that were ball milled in water and then were subjected to sonofragmentation showed practically the same crystal size as sample that was just milled. Only sample $\mathrm{M}_{10} \mathrm{U}_{100} \mathrm{t}=5 \mathrm{~h}$, that was treated for $5 \mathrm{~h}$ with a $100 \%$ of wave amplitude, had a smaller crystallite, in this case, size was reduce until $24.5 \mathrm{~nm}$. The smaller crystallite was found to be $19.3 \mathrm{~nm}$, this could mean that a limit was reached because a particle limit size is reached ${ }^{31-32}$.

The Figure 2 shows thermograms of SA and samples after first and second attrition, degradation temperature $\left(\mathrm{T}_{\mathrm{d}}\right)$ of all samples are indicated in table 1 . As can be observed 
Table 1. Summary of results of X-ray diffraction and TGA analysis.

\begin{tabular}{|c|c|c|c|c|}
\hline & Sample & Crystallite size $(\mathrm{nm})$ & $1 \mathrm{St} \mathrm{Wt} \mathrm{loss},{ }^{\circ} \mathrm{C}$ & $\operatorname{Td}\left({ }^{\circ} \mathrm{C}\right)^{*}$ \\
\hline & Stearic acid & --- & --- & 274.1 \\
\hline & B & 51.9 & --- & 795.4 \\
\hline & M10 & 30.1 & --- & 734.7 \\
\hline & M10U50 t=1h & 32.3 & --- & 737.0 \\
\hline \multirow[t]{5}{*}{ Grinded in water } & M10U100 t=1h & 31.3 & --- & 733.2 \\
\hline & M10U50 t=5h & 32.7 & --- & 732.5 \\
\hline & M10U100 t $=5 \mathrm{~h}$ & 24.5 & --- & 727.4 \\
\hline & C-M10 & 23.3 & 454.9 & 724.7 \\
\hline & C- M10U50 t=1h & 19.3 & 448.3 & 730.6 \\
\hline \multirow[t]{3}{*}{ Grinded in stearic acid } & C-M10U100 t=1h & 25.6 & 467.6 & 736.5 \\
\hline & C-M10U50 t=5h & 23.4 & 461.5 & 730.0 \\
\hline & C-M10U100 t=5h & 29.9 & 456.6 & 734.9 \\
\hline
\end{tabular}

*1st weight loss= first step of decomposition, $\mathrm{Td}=$ main decomposition step

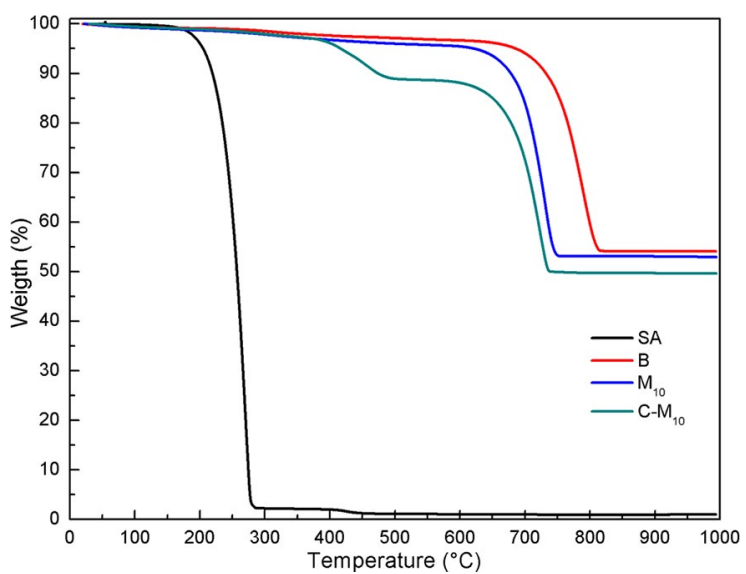

Figure 2. TGA thermogram of stearic acid (SA), eggshell (B), ball milled $\left(\mathrm{M}_{10}\right)$ and ball milled $\mathrm{SA}\left(\mathrm{C}-\mathrm{M}_{10}\right)$.

in Fig. 2, there is only one step during thermal degradation for SA meaning that this fatty acid is decomposed in one step leaving $2 \mathrm{wt} \%$ of residues. The $\mathrm{T}_{\mathrm{d}}$ for $\mathrm{SA}$ according to DSC was $274.1^{\circ} \mathrm{C}$. For samples $B$ and $M_{10}$ there is also one degradation step, but for sample coated with SA in a ball mill $\left(\mathrm{C}-\mathrm{M}_{10}\right)$ the first weight lost appears at $454.9^{\circ} \mathrm{C}$. Hence, there has been adsorption of $\mathrm{SA}$ on $\mathrm{CaCO}_{3}$ surface during the milling, the $\mathrm{SA}$ can be adsorbed by $\mathrm{CaCO}_{3}$ when a wet method is employed ${ }^{28}$. For these materials it was found 3 degradation steps in a DTA analysis from a region between 200 and $400{ }^{\circ} \mathrm{C}$; one below the $\mathrm{T}_{\mathrm{d}}$ of SA related to weak bonds between the organic acid and $\mathrm{CaCO}_{3}$ (physisorption), another one around SA's $\mathrm{T}_{\mathrm{d}}$ attributed to free SA, and a last one above the degradation temperature of the acid, associated with strong bonds or chemisorption. When dry milling method was employed, the ion calcium $(-\mathrm{Ca}+)$ joins an acid molten molecule to form calcium stearate and bicarbonate ${ }^{33}$. Since for sample C-M $\mathrm{M}_{10}$ there is only one step before the conversion from calcium carbonate to calcium oxide $(\mathrm{CaO})$ and this step take place in a temperature above the $\mathrm{T}_{\mathrm{d}}$ of SA, a chemisorption has been occurred during the dry milling ${ }^{28,34}$, SA does not physically absorb on $\mathrm{CaCO}_{3}$ surface during dry milling ${ }^{35}$ due to a combination of high temperature and high energy impacts by balls during the milling.

This phenomenon also appears in thermograms for samples $\mathrm{C}-\mathrm{M}_{10}$ after sonofragmentation (Figure 3 ), therefore, the chemisorption effect and the "fused" layer are present after ultrasound passes thru samples. Hence, the amount of energy and time during ultrasound treatment, do not affect the bound between $\mathrm{CaCO}_{3}$ and $\mathrm{SA}$ formed during milling. It was also detected a loss of water of approximately $1 \% \mathrm{w}$ before $200^{\circ} \mathrm{C}$. For samples $\mathrm{M}_{10}$ there is a first section between 200 and $600{ }^{\circ} \mathrm{C}$ where a maximum of $5 \% \mathrm{w}$ was lost, this is caused by the thermal degradation of organic components that remain in the ceramic extracted from eggshell ${ }^{36}$.

$\mathrm{T}_{\mathrm{d}}$ results from Table 1 show that Sample $\mathrm{B}$ has a degradation temperature of $795.4^{\circ} \mathrm{C}$. As the crystallite size is reduced $T_{d}$ has the same effect, for smaller crystallites $T_{d}$ is lower, and for samples $\mathrm{M}_{10}$ and $\mathrm{C}-\mathrm{M}_{10} \mathrm{~T}_{\mathrm{d}}$ is 734.7 and 724.7 respectively. After sonofragmentation all samples ball milled at $10 \mathrm{~h}$ have the approximately the same $\mathrm{T}_{\mathrm{d}}$ and the same crystallite size, except sample ball milled at $10 \mathrm{~h}$. Therefore, the smaller the crystallite size the lower the decomposition temperature. But this tendency seams to break for samples $\mathrm{C}-\mathrm{M}_{10}$ after the ultrasound treatment. For these materials not a clear trend can be described.

Ball milling time seems to be the key to get finer nanoparticles; in Figure 4(a) sample $\mathrm{C}-\mathrm{M}_{10} \mathrm{U}_{50}$ with a sonofragmentation time of $1 \mathrm{~h}$ shows nanoparticles with no homogeneus distribution size but with smaller particles than sample $\mathrm{C}-\mathrm{M}_{10} \mathrm{U}_{100} \mathrm{t}=1 \mathrm{~h}$, that is displayed in Figure 4(b). When sonication time is increased to 5 hours (Figure 4(c) and Figure 4(d)) nanoparticles get together again molding bigger particles but with a different shape, almost as if they were experimented the cold welding effect or welding by collisions that metal nanoparticles show under certain 


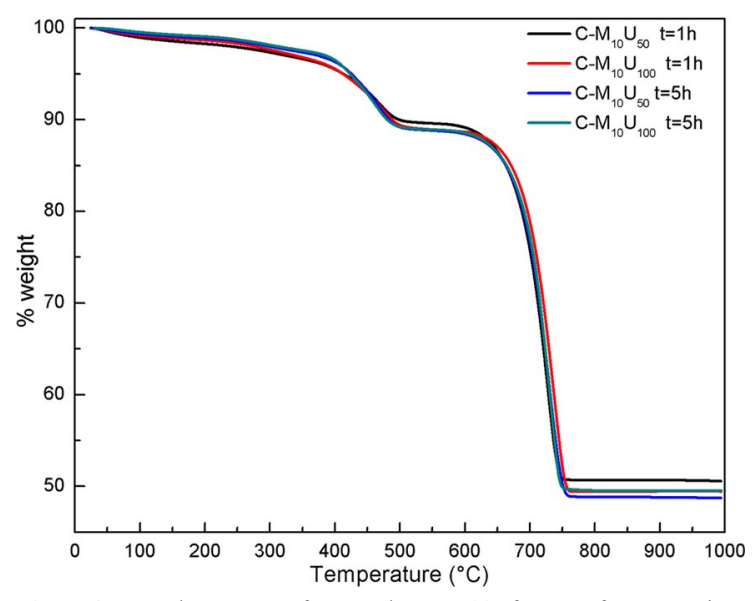

Figure 3. TGA thermogram for samples C-M10 after sonofragmentation. conditions like: plastic deformation ${ }^{37-38}$, ultrasonic spot welding (dry conditions), or by the influence of ultrasound in a liquid solution ${ }^{21}$.

The figure 5 shows TEM micrographs for particles grinded in water and SA sonicated with amplitude of $50 \%$ and $100 \%$, and sonication time of 1 and $5 \mathrm{~h}$. When sonication time increase, the particle shape changed from a figure similar to a rectangular prism to form a tube shape appearance (figure $5 \mathrm{a}$ and $5 \mathrm{~b}$ ), with a lenght of approximately $600 \mathrm{~nm}$. The figure 5(d) shows that these shapes could be tubes with a diameter of $100 \mathrm{~nm}$, but is not possible to confirm if they are hollow tubes. On the other hand, Figure 5(e) shows another type of filaments, in this micrograph the figures are not so similar to those shown above.

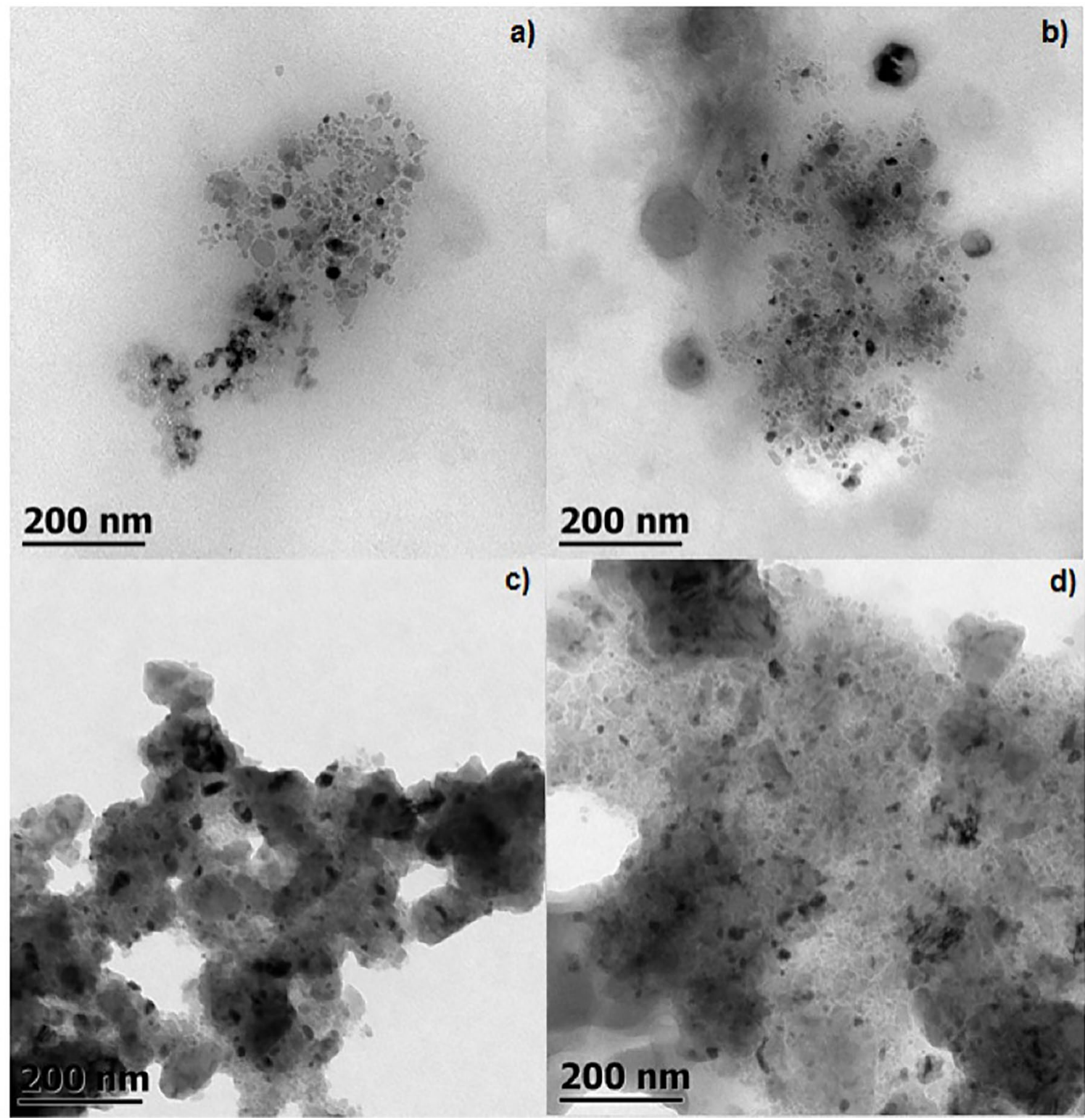

Figure 4. TEM micrographs of a) $\left.\left.C-M_{10} U_{50} t=1 h, b\right) C-M_{10} U_{100} t=1 h, c\right) M_{10} U_{50} t=5 h$ and e) $M_{10} U_{100} t=5 h$. 


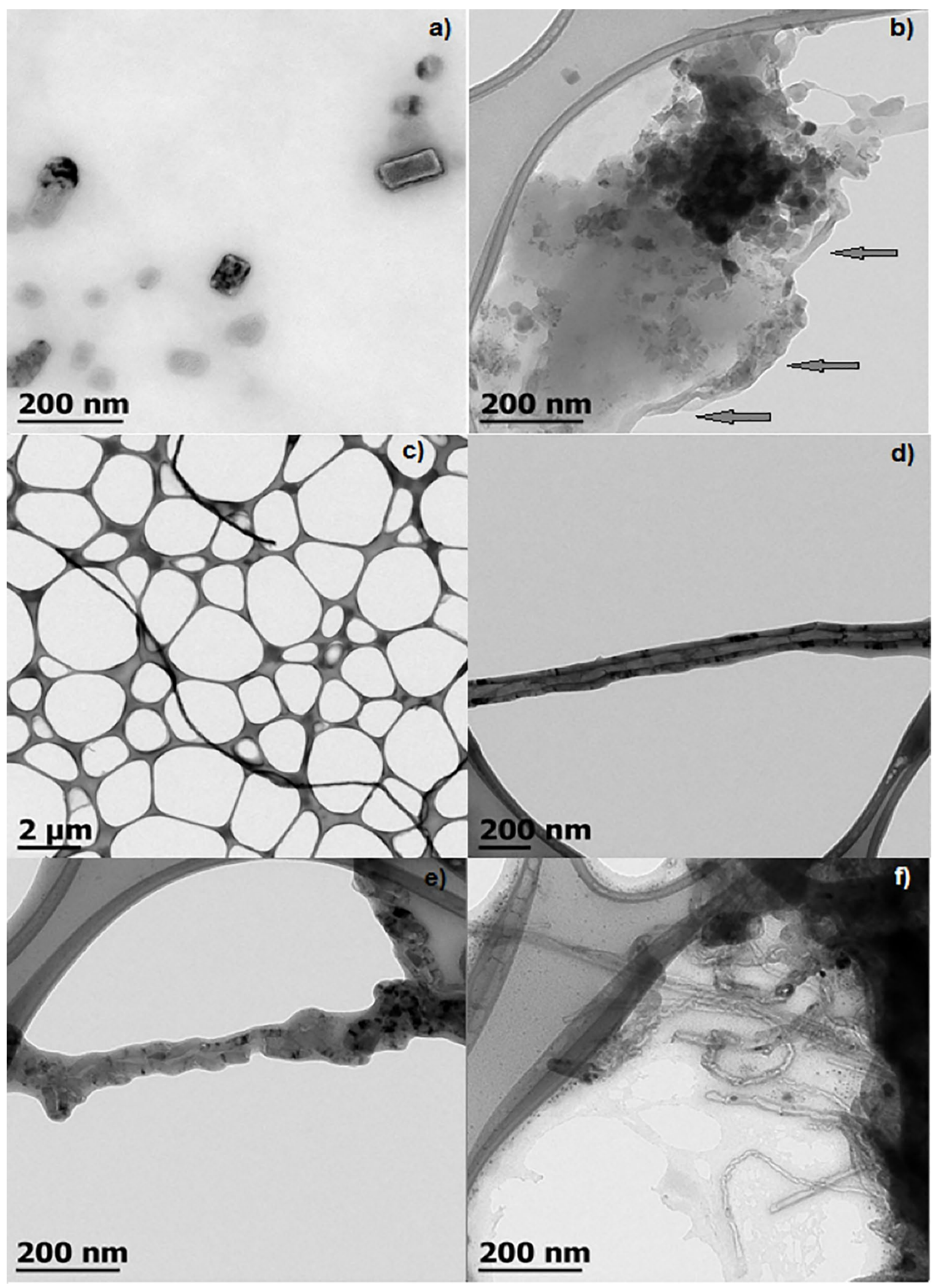

Figure 5. TEM micrographs of C-M10U75 a) sonicated for 3 hours; b), c), d), e) and f) sonicated for 5 hours. 
More exceptional TEM micrographs were obtained from this experiment and Figure 5(f) displays $\mathrm{CaCO}_{3}$ fibers-like shapes. There are reports of obtaining of rectangular prism in hydrothermal synthesis of aragonite ${ }^{39}$, but with a longer and narrower shape, they described them as whiskers. The synthesis of inorganic nanotubes has been known since $1992^{4}$ when it was reported the route of production of $\mathrm{WS}_{2}$ cylindrical structures. Since then, numerous layered compounds have been turned into tubes.

As well some authors have been able to synthesize $\mathrm{CaCO}_{3}$ showing several shapes like rods and spheres with an aragonite and vaterite crystalline structure respectively, aragonite with tubes or whiskers shapes ${ }^{39}$, flakes of vaterite or aragonite, or in some cases a mixture of both structures ${ }^{40-41}$, but, in all cases the $\mathrm{CaCO}_{3}$ was obtained by a chemical reaction.

\section{Conclusions}

The use of a surfactant during the ball milling of eggshell reduces the time and wave amplitude needed to get a smaller grain size. A grinding limit was reached with ten hours of milling in stearic acid and 1 hour of sonofragmentation. The presence of stearic acid creates two degradation steps, and a smaller crystallite reduces the degradation temperature of $\mathrm{CaCO}_{3}$. The microscopy study reveals superplasticity activity when 5 hours of ultrasound is applied to this ceramic. It also shows that an exfoliation took place during the whole process, giving place to the development of prisms and tubular $\mathrm{CaCO}_{3}$ shapes. A mechanical route can be followed in the preparation of nanotubes of calcite.

\section{Acknowledgments}

The authors would like to thank The authors wish to thank the Laboratorio Nacional de Nanotecnología (Nanotech) for the facilities provided and to Carlos Ornelas and Ernesto Guerrero for its valuable collaboration during the present research for their support in the use of the facilities.

\section{References}

1. Dávalos-Saucedo CA, Rossi-Márquez G, Regalado-González C, Alonzo-Macías M, Di Pierro P. Application of Transglutaminase Crosslinked Whey Protein-Pectin Coating Improves Egg Quality and Minimizes the Breakage and Porosity of Eggshells. Coatings. 2018;8(12):438.

2. Soares MA, Marto S, Quina M, Gando-Ferreira L, QuintaFerreira R. Evaluation of Eggshell-Rich Compost as Biosorbent for Removal of $\mathrm{Pb}$ (II) from Aqueous Solutions. Water, Air, \& Soil Pollution. 2016;227:150.
3. D'Souza SF, Kumar J, Jha SK, Kubal BS. Immobilization of the urease on eggshell membrane and its application in biosensor. Materials Science Engineering: C. 2013;33(2):850-854.

4. Chen X, Zhu Y, Zhou B, Guo Y, Gao W, Ma Y, et al. Hydrophilic $\mathrm{CaCO} 3$ nanoparticles designed for poly(ethylene terephthalate). Powder Technology. 2010;204(1):21-26.

5. Tanniru M, Misra RDK. On enhanced impact strength of calcium carbonate-reinforced high density polyethylene composites. Materials Science and Engineering: A. 2005;405(1-2):178-193.

6. Chan CM, Wu J, Li XJ, Cheung YK. Polypropylene/calcium carbonate nanocomposites. Polymer. 2002;43(10):2981-2992.

7. Wu WS, Queiroz ME, Mohallem NDS. The effect of precipitated calcium carbonate nanoparticle in coatings. Journal of Coatings Technology Research. 2016;13(2):277-286.

8. Nan Z, Chen X, Yang Q, Wang X, Shi Z, Hou W. Structure transition from aragonite to vaterite and calcite by the assistance of SDBS. Journal of Colloid and Interface Science. 2008;325(2):331-336

9. Hassan TA, Rangari VK, Rana RK, Jeelani S. Sononchemical effect on size reduction of $\mathrm{CaCo} 3$ nanoparticles derived from waste eggshells. Ultrasonics Sonochemistry. 2013;20(5):13081315 .

10. Mosaddegh E. Ultrasonic-assisted preparation of nano eggshell powder: A novel catalyst in green and high efficient synthesis of 2-aminochromenes. Ultrasonics Sonochemistry. 2013;20(6):1436-1441.

11. Rangari VK, Hassan TA, Mayo Q, Jeelani S. Size reduction of $\mathrm{WO}_{3}$ nanoparticles by ultrasound irradiation and its applications in structural nanocomposites. Composites Science and Technology. 2009;69(14):2293-2300.

12. Gopi KR, Nagarajan R. Advances in Nanoalumina Ceramic Particle Fabrication Using Sonofragmentation. IEEE Transactions on Nanotechnology. 2008;7(5):532-537.

13. Suslick KS. Sonochemistry. Science. 1990;247(4949):14391445 .

14. Ashokkumar M. The characterization of acoustic cavitation bubbles --An overview. Ultrasonics Sonochemistry. 2011;18(4):864-872.

15. Suslick KS. The Chemical Effects of Ultrasound. Scientific American. 1989;260:80-87.

16. Sander JRG, Zeiger BW, Suslick KS. Sonocrystallization and sonofragmentation. Ultrasonics Sonochemistry. 2014;21(6):19081915.

17. Thompson LH, Doraiswamy LK. Sonochemistry: Science and Engineering. Industrial \& Engineering Chemistry Research. 1999;38(4):1215-1249.

18. O'Sullivan JJ, Park M, Beevers J, Greenwood RW, Norton IT. Applications of ultrasound for the functional modification of proteins and nanoemulsion formation: A review. Food Hydrocolloids. 2017;71:299-310.

19. Mason TJ, Peters D, eds. Practical Sonochemistry: Power Ultrasound Uses and Applications. Philadelphia: Woodhead Publishing; 2002. 
20. Prozorov T, Prozorov R, Suslick KS. High Velocity Interparticle Collision Driven by Ultrasound. Journal of the American Chemical Society. 2004;126(43):13890-13891.

21. Mason TJ, Lorimer JP. An Introduction to Sonochemistry. Endeavour. 1989;13(3):123-128.

22. Zeiger BW, Suslick KS. Sonofragmentation of Molecular Crystals. Journal of the American Chemical Society. 2011;133(37):1453014533.

23. Okada K, Nagashima T, Kameshima Y, Yasumori A. Effect of crystallite size on the thermal phase change and porous properties of boehmite. Journal of Colloid and Interface Science. 2002;248(1):111-115.

24. Banerjee A, Das A, Das D, Saha A, Sarkar S. Mössbauer study of Fe-doped BaTiO3 of different grain sizes induced by ball mill technique. Journal of Magnetism and Magnetic Materials. 2018;449:180-184.

25. Maweja K, Phasha M, van der Berg N. Microstructure and crystal structure of an equimolar Mg-Ti alloy processed by Simoloyer high-energy ball mill. Powder Technology. 2010;199(3):256263.

26. Saviak MP, Mel'nik OB, Uvarova IV, Kotko AV, Udovik OO. Crystallographic Features of Nanosized Titanium Carbide Produced from Titanium and Carbon in a Planetary-Ball Mill. Powder Metallurgy and Metal Ceramics. 2016;55(5-6):251-258.

27. Toraman OY. Effect of chemical additive on stirred bead milling of calcite powder. Powder Technology. 2012;221:189-191.

28. Mihajlović S, Sekulic Ž, Daković A, Vučinić D, Jovanović V, Stojanović J. Surface properties of natural calcite filler treated with stearic acid. Ceramics-Silikáty. 2009;53(4):268-275.

29. Fox NJ, Stachowiak GW. Vegetable oil-based lubricants--A review of oxidation. Tribology International. 2007;40(7):10351046.

30. Kleinová A, Fodran P, Brnčalová L, Cvengroš J. Substituted esters of stearic acid as potential lubricants. Biomass and Bioenergy. 2008;32(4):366-371.
31. Armstrong P, Knieke C, Mackovic M, Frank G, Hartmaier A, Göken M, et al. Microstructural evolution during deformation of tin dioxide nanoparticles in a comminution process. Acta Materalia. 2009;57(10):3060-3071.

32. Hielscher T. Ultrasonic Production of Nano-Size Dispersions and Emulsions. In: European Nano Systems Worshop - ENS 2005; 2005 Dec 14-16; Paris, France.

33. Mihajlović SR, Vučinić DR, Sekulić ZT, Milićević SZ, Kolonja BM. Mechanism of stearic acid adsorption to calcite. Powder Technology. 2013;245:208-216.

34. Shi X, Rosa R, Lazzeri A. On the Coating of Precipitated Calcium Carbonate with Stearic Acid in Aqueous Medium. Langmuir. 2010;26(11):8474-8482.

35. Kow KW, Abdullah EC, Aziz AR. Effect of ultrasound in coating nano-precipitated $\mathrm{CaCO} 3$ with stearic acid. Asia-Pacific Journal of Chemical Engineering. 2009;4:807-813.

36. Boronat T, Fombuena V, Garcia-Sanoguera D, Sanchez-Nacher L, Balart R. Development of a biocomposite based on green polyethylene biopolymer and eggshell. Materials \& Design. 2015;68:177-185.

37. Liu L, Shen D, Zou G, Peng P, Zhou Y. Cold welding of Ag nanowires by large plastic deformation. Scripta Materialia. 2016;114:112-116.

38. Asano K, Enoki H, Akiba E. Synthesis process of Mg-Ti BCC alloys by means of ball milling. Journal of Alloys and Compounds. 2009;486(1-2):115-123.

39. Xie RJ, Mitomo M, Zhan GD. Superplasticity in a fine-grained beta-silicon nitride ceramic containing a transient liquid. Acta Materialia. 2000;48(9):2049-2058.

40. Tenne R, Margulis L, Genut M, Hodes G. Polyhedral and cylindrical structures of tungsten disulphide. Nature. 1992;360:444-446.

41. Kuang M, Wang D, Gao M, Hartmann J, Möhwald H. A BioInspired Route to Fabricate Submicrometer-Sized Particles with Unusual Shapes - Mineralization of Calcium Carbonate within Hydrogel Spheres. Chemistry of Materials. 2005;17(3):656-660. 